\title{
Chronic Kidney Disease and Associated Risk Factors Assessment among Diabetes Mellitus Patients at A Tertiary Hospital, Northwest Ethiopia
}

\author{
Shewaneh Damtie ${ }^{1}$, Belete Biadgo ${ }^{1}$, Habtamu Wondifraw Baynes ${ }^{1}$, Sintayehu \\ Ambachew $^{1}$, Tadele Melak ${ }^{1}$, Daniel Asmelash ${ }^{1}$, Molla Abebe ${ }^{1^{*}}$
}

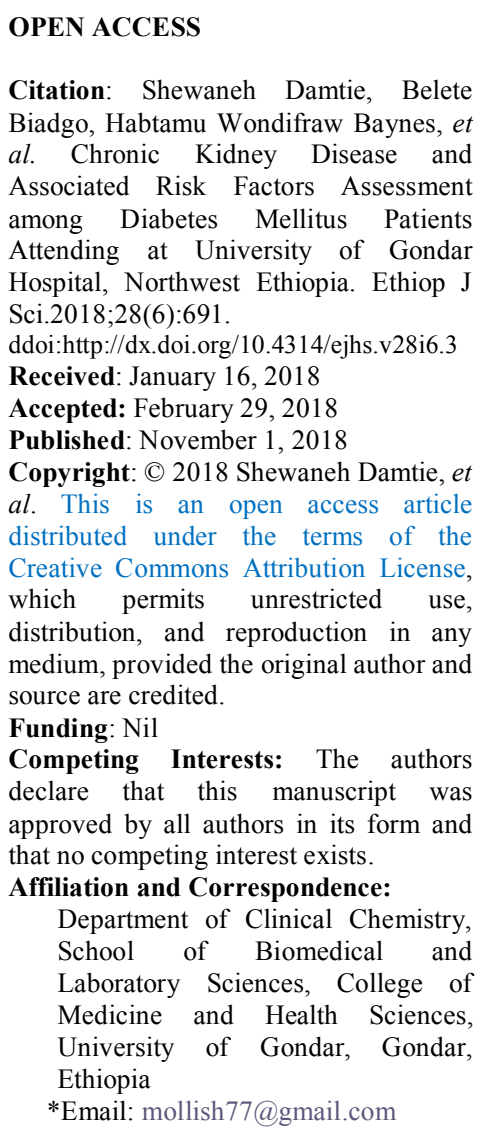

Citation: Shewaneh Damtie, Belete Biadgo, Habtamu Wondifraw Baynes, et al. Chronic Kidney Disease and Associated Risk Factors Assessment among Diabetes Mellitus Patients Attending at University of Gondar Hospital, Northwest Ethiopia. Ethiop J Sci.2018;28(6):691

ddoi:http://dx.doi.org/10.4314/ejhs.v28i6.3

Received: January 16, 2018

Accepted: February 29, 2018

Published: November 1, 2018

Copyright: (C) 2018 Shewaneh Damtie, et al. This is an open access article distributed under the terms of the Creative Commons Attribution License, which permits unrestricted use, distribution, and reproduction in any medium, provided the original author and source are credited.

Funding: Nil

Competing Interests: The authors declare that this manuscript was approved by all authors in its form and that no competing interest exists. Affiliation and Correspondence: Department of Clinical Chemistry, School of Biomedical and Laboratory Sciences, College of Medicine and Health Sciences, University of Gondar, Gondar, Ethiopia

*Email:mollish77@gmail.com

\section{ABSTRACT}

BACKGROUND: The prevalence of chronic kidney disease, particularly in diabetic patients, is increasing rapidly throughout the world. Nowadays, many individuals in developing nations are suffering from diabetes which is one of the primary risk factors of chronic kidney disease.

METHODS: Institution based cross-sectional study was conducted at the University of Gondar Hospital from February to April 2016. A total of 229 study participants were selected using systematic random sampling technique. Urine sample was collected for albumin determination by dipstick. The Simplified Modification of Diet in Renal Disease study equation was used to estimate glomerular filtration rate. Binary logistic regression model was used to identify risk factors.

RESULTS: Of the total 229 study participants, 50.2\% were females and the mean age was $47 \pm 15.7$ years. Among study participants, the prevalence of chronic kidney disease (CKD) was found to be $21.8 \%$ (95\% CI: $16 \%$ - 27\%). Of all study participants, 9(3.9\%) had renal impairment (eGFR $\left.<60 \mathrm{ml} / \mathrm{min} / 1.73 \mathrm{~m}^{2}\right)$ and 46 (20.1\%) had albuminuria. Older age (AOR: 5.239, 95\% CI: 2.255-12.175), systolic blood pressure $\geq 140 \mathrm{mmHg}$ (AOR: 3.633, 95\% CI: 1.597-8.265), type 2 diabetes mellitus (AOR: 3.751, 95\% CI: 1.507-9.336) and longer duration of diabetes (AOR: 3.380, 95\% CI: 1.393-8.197) were independent risk factors of CKD.

CONCLUSIONS: The study identified high prevalence (21.8\%) of CKD among diabetic adults. CKD was significantly associated with older age, systolic blood pressure, type $2 \mathrm{DM}$ and longer duration of DM. Thus, DM patients should be diagnosed for chronic kidney disease and then managed accordingly.

KEYWORDS: Chronic kidney disease, Diabetes mellitus, Glomerular filtration rate, Risk factors

\section{INTRODUCTION}

Chronic kidney disease (CKD) is a progressive loss in renal function over a period of three months or years. Kidneys can get damaged from a physical injury or a disease like diabetes mellitus (DM) or high blood pressure. Once kidneys are damaged, they cannot filter 
blood or perform other activities. This is usually associated with a reduction in glomerular filtration rate (GFR) and proteinuria $(1,2)$.

CKD is a worldwide public health problem, both for the number of patients and cost of treatment involved. It was a cause of 409,000 and 956,000 deaths in 1990 and 2013, respectively. Of those deaths, 46,000 (1990) and 173,000 (2013) were caused by CKD due to DM (3). Globally, diseases of the kidney and urinary tract together are the $12^{\text {th }}$ cause of death and the $17^{\text {th }}$ cause of disability (4). CKD affects around $10-13 \%$ of the general population (5). It has been estimated that more than 500 million individuals globally have CKD, regardless of the cause (6). In sub-Saharan Africa, $\mathrm{CKD}$ is a considerable health burden. CKD is at least 3-4 times more frequent in Africa than in developed world (7).

CKD is associated with adverse outcomes of kidney failure, cardiovascular disease (CVD), and premature death $(5,8)$. The risk of cardiovascular mortality, kidney failure, kidney-disease progression, acute kidney injury, cognitive decline, anaemia, mineral and bone disorders, fractures and hospitalizations are higher among patients with CKD than those with normal renal function $(9,10)$. Many of the complications of CKD can be prevented or delayed by early detection and treatment (11).

Major risk factors for the development and progression of CKD are diabetes and hypertension. CKD due to diabetes and hypertension affects nearly $5-7 \%$ of the world population and is more common in developing countries and disadvantaged and minority populations (12). Diabetes causes $9.1-29.9 \%$ of the cases of end stage renal disease (ESRD) in various developing countries, and hypertension leads to $13-21 \%$ of the cases (13). Hypertension affects almost $25 \%$ of the adult population in Africa and is the cause of chronic kidney failure in $21 \%$ of patients on renal replacement therapy in South Africa. The prevalence of diabetic nephropathy is estimated to be $23.8 \%$ in Zambia, $14 \%-16 \%$ in South Africa, $12.4 \%$ in Egypt, $9 \%$ in Sudan, and 6.1\% in Ethiopia (7).
CKD is an important cause of death and disability worldwide, but awareness of the disorder remains low in many communities and among many healthcare providers (10). The prevalence of DM is increasing alarmingly in developing countries like Ethiopia (14). In parallel, CKD will increase even if studies did not show the exact magnitude particularly in the study area, Gondar. Therefore, this study was aimed to assess the prevalence of CKD and associated risk factors among DM patients attending at University of Gondar Hospital, Northwest Ethiopia.

\section{MATERIALS AND METHODS}

Population and study design: The study was conducted at the University of Gondar Hospital Chronic Illness Clinic, Gondar, Northwest Ethiopia. Adult ( $\geq 18$ years) DM patients who volunteered to give informed written consent were included in the study. Pregnant, hospitalized, nonfasting, febrile patients, and patients with HIV and CVD were excluded. Institution based crosssectional study was conducted from February to April 2016.

Data collection: The sample size was calculated using single population proportion formula considering 18.2\% CKD prevalence in Southern Ethiopia (15) and assumptions of 5\% margin of error, $10 \%$ non-response rate and $95 \%$ level of confidence. Even though, 252 study participants were assumed to be included, only 229 volunteered to give informed written consent to participate in the study. Study participants were selected by systematic random sampling technique.

Socio-demographic, clinical and anthropometric data were collected by nurses after the participants agreed to sign written consent. Height was measured using standiometer, and weight was recorded using a balace with patients being bare-footed and wearing light clothes. Body mass index (BMI) was calculated as weight divided by height squared $\left(\mathrm{kg} / \mathrm{m}^{2}\right)$. Underweight, normal weight, overweight and obese were 
classified as BMI <18.5, 18.5- 24.9, 25-29.9 and $\geq 30$, respectively.

Blood pressure was measured by nurses using an analogue sphygmomanometer and stethoscope. Measurements were taken from the upper arm while placing the hand at the heart level after the patients had been sitting for more than 5 minutes. Systolic blood pressure $\geq 140$ $\mathrm{mmHg}$ and/or diastolic blood pressure $\geq 90 \mathrm{mmHg}$ or current uses of blood pressure-lowering medication were used to define hypertension (16). Considering their current fasting blood glucose (FBG) level, participants were classified as with good glycemic control (FBG $<150 \mathrm{mg} / \mathrm{dl}$ ) and poor glycemic control (FBG $\geq 150 \mathrm{mg} / \mathrm{dl}$ ) (15).

Laboratory technologists collected blood and urine samples, and performed biochemical tests. Five milliliters of fasting venous blood sample was collected with standard venipuncture technique to separate serum. Mindray BS-200 (Shenzen Mindray Bio-Medical electronics Co. Ltd, China) analyzer was used for biochemical analysis. Serum glucose, creatinine and urea level were measured using the enzymatic glucose oxidase, kinetic alkaline picrate and enzymatic glutamate-dehydrogenase (GLDH) methods, respectively. Ten milliliters of freshly voided urine was collected by clean and dry container. Then, urine albumin was determined by using dipsticks (COMBINA 11S, Human). Presence of albumin in the urine (from +1 to +4 ) was defined as albuminuria.

The glomerular filtration rate (GFR) was estimated using Modification of Diet in Renal Disease (MDRD) study equation as follow: $186 \times$ [serum creatinine $\left.\left(\frac{\mathrm{mg}}{\mathrm{dl}}\right)\right]^{-1.154} \times(\text { age })^{-0.203} \times$ (0.742 if female) $\mathrm{x}$ (1.212, if black) (17). CKD was defined incorporating both eGFR and albuminuria. Patients having CKD were classified into five stages according to the Kidney Disease: Improving Global Outcomes (KDIGO) classification system as follows: stage 1: albuminuria with eGFR of $\geq 90 \mathrm{ml} / \mathrm{min} / 1.73 \mathrm{~m}^{2}$, stage 2: albuminuria with eGFR of $60-89$ $\mathrm{ml} / \mathrm{min} / 1.73 \mathrm{~m}^{2}$, stage 3 : eGFR of $30-59$ $\mathrm{ml} / \mathrm{min} / 1.73 \mathrm{~m}^{2}$, stage 4 : eGFR of $15-29$ $\mathrm{ml} / \mathrm{min} / 1.73 \mathrm{~m}^{2}$ and stage 5 (kidney failure): eGFR of $<15 \mathrm{ml} / \mathrm{min} / 1.73 \mathrm{~m}^{2}$. Stage 3 was further classified into 3A (eGFR of $45-59.9 \mathrm{ml} / \mathrm{min} / 1.73$ $\mathrm{m}^{2}$ ) and 3B (eGFR of $30-44.9 \mathrm{ml} / \mathrm{min} / 1.73 \mathrm{~m}^{2}$ ) (1).

Data analysis: Data were checked, sorted, categorized and coded manually. Then, data were entered into EPI info version 3.5.3 and then transferred to SPSS version 20 for analysis. Bivariate and multivariate logistic regression models were used to assess associated risk factors. Variables with a p-value of $\leq 0.2$ in the bivariate analysis were remained in the multivariate logistic regression model to control the effect of confounding variables and to identify independent risk factors of CKD. Both crude and adjusted odds ratios with their $95 \%$ confidence intervals (CI) were computed to measure the strengths of associations between variables. A p-value of $<0.05$ was considered as statistically significant.

Ethics approval: Ethical clearance was obtained from Research and Ethical Review Committee of School of Biomedical and Laboratory Sciences, College of Medicine and Health Sciences, University of Gondar. Permission letter was also taken from the clinical dDirector of the hospital and head of the DM clinic. To ensure confidentiality of the study participants' information, anonymous typing was applied so that the name of the participants and any identifier was not written on the questionnaire. Data were collected after full written consent had been obtained from each participant. Patients with abnormal test results were consulted to consult physicians for further diagnosis and treatment accordingly.

\section{RESULTS}

Socio-demographic and clinical characteristics: The mean age of the study participants was $47 \pm 15.7$ years. The majority, $184(80.3 \%)$, of the participants were $\leq 60$ years old, $182(79.5 \%)$ were urban dwellers, 202(88.2\%) were Orthodox Christianity followers and 130(56.8\%) were married (Table 1). 
Table 1: Socio-demographic characteristics

\begin{tabular}{|c|c|c|c|}
\hline Characteristics & & Number & Percent \\
\hline \multirow[t]{2}{*}{ Age (year) } & $\leq 60$ & 184 & 80.3 \\
\hline & $>60$ & 45 & 19.7 \\
\hline \multirow[t]{2}{*}{ Sex } & Male & 114 & 49.8 \\
\hline & Female & 115 & 50.2 \\
\hline \multirow[t]{3}{*}{ Religion } & Orthodox & 202 & 88.2 \\
\hline & Muslim & 23 & 10.0 \\
\hline & Protestant & 4 & 1.8 \\
\hline \multirow[t]{2}{*}{ Residence } & Urban & 182 & 79.5 \\
\hline & Rural & 47 & 20.5 \\
\hline \multirow[t]{4}{*}{ Marital status } & Single & 35 & 15.3 \\
\hline & Married & 130 & 56.8 \\
\hline & Widowed & 43 & 18.8 \\
\hline & Divorced & 21 & 9.2 \\
\hline \multirow[t]{4}{*}{ Educational status } & No education & 95 & 41.5 \\
\hline & Primary school & 64 & 27.9 \\
\hline & Secondary school & 38 & 16.6 \\
\hline & Higher education and above & 32 & 14.0 \\
\hline \multirow[t]{6}{*}{ Occupation } & Merchant & 18 & 7.9 \\
\hline & Housewife & 61 & 26.6 \\
\hline & Government employed & 69 & 30.1 \\
\hline & Self-employed & 22 & 9.6 \\
\hline & Farmer & 42 & 18.3 \\
\hline & Others & 17 & 7.4 \\
\hline \multirow[t]{5}{*}{ Income (Ethiopian birr) } & $<1001$ & 124 & 54.1 \\
\hline & $1001-2000$ & 47 & 20.5 \\
\hline & $2001-3000$ & 26 & 11.4 \\
\hline & $3001-4000$ & 11 & 4.8 \\
\hline & $>4000$ & 21 & 9.2 \\
\hline
\end{tabular}

Among the study participants, 119(52\%) had type $2 \mathrm{DM}$ and 101(44.1\%) had hypertension. Family history of CKD was found in 30(13.1\%) participants. The majority of the participants,
$133(58.1 \%)$, were classified as normal weight, 216(94.3\%) never smoked and 168(73.4\%) had no alcohol consumption habit (Table 2). 
Table 2: Clinical and behavioral characteristics

\begin{tabular}{|c|c|c|c|}
\hline Characteristics & & Number & Percent \\
\hline \multirow[t]{4}{*}{ Body mass index } & Underweight $(<18.5)$ & 22 & 9.6 \\
\hline & Normal weight (18.5-24.9) & 133 & 58.1 \\
\hline & Overweight (25-29.9) & 54 & 23.6 \\
\hline & Obese $(\geq 30)$ & 20 & 8.7 \\
\hline \multirow[t]{2}{*}{ Systolic blood pressure } & $<140 \mathrm{mmHg}$ & 163 & 71.2 \\
\hline & $\geq 140 \mathrm{mmHg}$ & 66 & 28.8 \\
\hline \multirow[t]{2}{*}{ Diastolic blood pressure } & $<90 \mathrm{mmHg}$ & 209 & 91.3 \\
\hline & $\geq 90 \mathrm{mmHg}$ & 20 & 8.7 \\
\hline \multirow[t]{2}{*}{ Hypertension } & Present & 101 & 44.1 \\
\hline & Absent & 128 & 55.9 \\
\hline \multirow[t]{2}{*}{ Waist circumference } & Low risk & 155 & 67.7 \\
\hline & High risk & 74 & 32.3 \\
\hline \multirow[t]{2}{*}{ Types of diabetes } & Type 1 & 110 & 48.0 \\
\hline & Type 2 & 119 & 52.0 \\
\hline \multirow[t]{2}{*}{ Duration of diabetes } & $<10$ years & 179 & 79.2 \\
\hline & $\geq 10$ years & 50 & 21.8 \\
\hline \multirow[t]{2}{*}{ Family history of kidney disease } & Yes & 30 & 13.1 \\
\hline & No & 199 & 86.9 \\
\hline \multirow[t]{3}{*}{ Smoking habit } & Never smoked & 216 & 94.3 \\
\hline & Smoker & 4 & 1.7 \\
\hline & ex-smoker & 9 & 3.9 \\
\hline \multirow[t]{2}{*}{ Alcohol consumption habit } & Yes & 61 & 26.6 \\
\hline & No & 168 & 73.4 \\
\hline \multirow[t]{2}{*}{ Fasting blood sugar } & $<150 \mathrm{mg} / \mathrm{dl}$ & 102 & 45.5 \\
\hline & $\geq 150 \mathrm{mg} / \mathrm{dl}$ & 127 & 55.5 \\
\hline \multirow[t]{2}{*}{ Urea level } & Normal $(\leq 40 \mathrm{mg} / \mathrm{dl})$ & 215 & 93.9 \\
\hline & $\operatorname{High}(>40 \mathrm{mg} / \mathrm{dl})$ & 14 & 6.1 \\
\hline \multirow[t]{2}{*}{ Urine albumin } & Negative & 183 & 79.9 \\
\hline & Positive & 46 & 20.1 \\
\hline \multirow[t]{2}{*}{ Chronic kidney disease } & Present & 50 & 21.8 \\
\hline & Absent & 179 & 78.2 \\
\hline
\end{tabular}

Prevalence of CKD: The estimated prevalence of CKD was $21.8 \%$ (95\% CI: $16 \%$ - 27\%). Of all the study participants, $9(3.9 \%)$ had renal impairment $\left(\mathrm{eGFR}<60 \mathrm{~mL} / \mathrm{min} / 1.73 \mathrm{~m}^{2}\right)$ and $46(20.1 \%)$ had albuminuria (Table 2). All of the participants who had renal impairment and the majority of the participants with albminuria $(37 / 46,80 \%)$ were type 2 DM patients (Table 3 ).

Table 3: Prevalence and stages of CKD

\begin{tabular}{|c|c|c|c|}
\hline Stage & Description & eGFR $\left(\mathrm{ml} / \mathrm{min} / 1.73 \mathrm{~m}^{2}\right)$ & $\mathrm{N}(\%)$ \\
\hline 1 & Normal eGFR with albuminuria & $\geq 90$ & $9(3.9)$ \\
\hline 2 & Slightly decreased eGFR with albuminuria & $60-89.9$ & $32(14.0)$ \\
\hline 3 & Moderately decreased eGFR & $30-59.9$ & $8(3.5)$ \\
\hline $3 \mathrm{~A}$ & Mildly to moderately decreased eGFR & $45-59.9$ & $5(2.2)$ \\
\hline $3 \mathrm{~B}$ & Moderately to severely decreased eGFR & $30-44.9$ & $3(1.3)$ \\
\hline 4 & Severely decreased eGFR & $15-29.9$ & $0(0)$ \\
\hline 5 & $\begin{array}{l}\text { Kidney failure } \\
\text { Total }\end{array}$ & $<15$ & $\begin{array}{l}1(0.4) \\
50(21.8)\end{array}$ \\
\hline
\end{tabular}

eGFR: estimated glomerular filtration rate, N: number, \%: percent

DOI: http://dx.doi.org/10.4314/ejhs.v28i6.3 
Associated risk factors of CKD: In the bivariate analysis, older age, obesity, elevated systolic blood pressure (SBP), hypertension, increased waist circumference (WC), type $2 \mathrm{DM}$, longer duration of diabetes and family history of kidney disease were found to be significantly associated with CKD.

The multivariable logistic regression analysis showed that older age, elevated SBP, increased WC, type $2 \mathrm{DM}$, and longer duration of diabetes were independently associated with CKD. The odds of CKD was
5.239 (AOR: $5.239,95 \%$ CI: 2.255-12.175) times higher among DM patients aged $>60$ years compared with DM patients $\leq 60$ years of age. Patients having SBP $\geq 140 \mathrm{mmHg}$ were 3.633 (AOR: 3.633, 95\% CI: 1.597-8.265) times more likely to develop CKD than having SBP $<140 \mathrm{mmHg}$. Furthermore, patients with type 2 $\mathrm{DM}$ and longer duration of diabetes were 3.751 (AOR: 3.751, 95\% CI: 1.507-9.336) and 3.380 (AOR: 3.380, 95\% CI: 1.393-8.197) times more likely to be affected by CKD than counterparts, respectively (Table 4).

Table 4: Factors associated with CKD

\begin{tabular}{|c|c|c|c|c|c|c|c|}
\hline \multirow{2}{*}{\multicolumn{2}{|c|}{ Variables }} & \multirow{2}{*}{\multicolumn{2}{|c|}{ CKD }} & \multirow[t]{2}{*}{ COR $(95 \% \mathrm{CI})$} & \multirow[t]{2}{*}{ P-value } & \multirow[t]{2}{*}{$\operatorname{AOR}(95 \% \mathrm{CI})$} & \multirow[t]{2}{*}{ P-value } \\
\hline & & & & & & & \\
\hline \multirow[t]{2}{*}{ Age } & $\leq 60$ years & $23(10)$ & $161(70.3)$ & 1.00 & & 1.00 & \\
\hline & $>60$ years & $27(11.8)$ & $18(7.9)$ & $10.5(5.013-21.992)$ & 0.000 & $5.239(2.255-12.175)$ & 0.000 \\
\hline \multirow[t]{2}{*}{ Sex } & Male & $20(8.7)$ & $94(41)$ & 1.00 & & & \\
\hline & Female & $30(13.1)$ & $85(37.1)$ & $1.659(0.877-3.138)$ & 0.120 & & \\
\hline \multirow[t]{3}{*}{ BMI } & $\leq 24.9$ & $32(14)$ & $123(53.7)$ & 1.00 & & 1.00 & \\
\hline & $25-29.9$ & $9(3.9)$ & $45(19.7)$ & $0.769(0.340-1.736)$ & 0.527 & $0.226(0.067-0.758)$ & 0.016 \\
\hline & $\geq 30$ & $9(3.9)$ & $11(4.8)$ & $3.145(1.201-8.238)$ & 0.02 & $0.992(0.255-3.860)$ & 0.991 \\
\hline \multirow[t]{2}{*}{ Systolic BP } & $<140 \mathrm{mmHg}$ & $23(10)$ & $140(61.1)$ & 1.00 & & 1.00 & \\
\hline & $\geq 140 \mathrm{mmHg}$ & $27(11.8)$ & $39(17)$ & $4.214(2.179-8.151)$ & 0.000 & $3.633(1.597-8.265)$ & 0.002 \\
\hline \multirow[t]{2}{*}{ Diastolic BP } & $<90 \mathrm{mmHg}$ & $44(19.2)$ & $165(72.1)$ & 1.00 & & & \\
\hline & $\geq 90 \mathrm{mmHg}$ & $6(2.6)$ & $14(6.1)$ & $1.607(0.584-4.424)$ & 0.358 & & \\
\hline \multirow[t]{2}{*}{ Hypertension } & Present & $36(15.7)$ & $65(28.4)$ & $4.51(2.266-8.977)$ & 0.000 & & \\
\hline & Absent & $14(6.1)$ & $114(49.8)$ & 1.00 & & & \\
\hline \multirow[t]{2}{*}{ WC } & Low risk & $24(10.5)$ & $131(52.7)$ & 1.00 & & & \\
\hline & High risk & $26(11.4)$ & $48(21)$ & $2.957(1.550-5.640)$ & 0.001 & $3.430(1.212-9.704)$ & 0.020 \\
\hline \multirow[t]{2}{*}{ Types of DM } & Type1 & $9(3.9)$ & $101(44.1)$ & 1.00 & & 1.00 & \\
\hline & Type2 & $41(17.9)$ & $78(34.1)$ & $5.899(2.705-12.863)$ & 0.000 & $3.751(1.507-9.336)$ & 0.004 \\
\hline \multirow[t]{2}{*}{ Duration of DM } & $<10$ years & $30(13.1)$ & $149(65.1)$ & 1.00 & & 1.00 & \\
\hline & $\geq 10$ years & $20(8.7)$ & $30(13.1)$ & $3.311(1.663-6.591)$ & 0.001 & $3.380(1.393-8.197)$ & 0.007 \\
\hline \multirow[t]{2}{*}{ FBS } & $<150 \mathrm{mg} / \mathrm{dl}$ & $17(7.4)$ & $85(37.1)$ & 1.00 & & & \\
\hline & $\geq 150 \mathrm{mg} / \mathrm{dl}$ & $33(14.4)$ & $94(41)$ & $1.755(0.912-3.378)$ & 0.092 & & \\
\hline \multirow[t]{2}{*}{ FH-KD } & Yes & $11(4.8)$ & $19(8.3)$ & $2.375(1.045-5.398)$ & 0.039 & & \\
\hline & No & $39(17)$ & $160(69.9)$ & 1.00 & & & \\
\hline \multirow{2}{*}{$\begin{array}{l}\text { Alcohol } \\
\text { consumption }\end{array}$} & Yes & $9(3.9)$ & $52(22.7)$ & $0.536(0.243-1.182)$ & 0.122 & & \\
\hline & No & $41(17.9)$ & $127(55.5)$ & 1.00 & & & \\
\hline
\end{tabular}

AOR: Adjusted odds ratio, BMI: Body mass index, BP: Blood pressure, CKD: Chronic kidney disease, COR: Crude odds ratio, DM: Diabetes mellitus, FBS: Fasting blood sugar, FH-KD: Family history of kidney disease, N: Number, P: P-value, WC: Waist circumference, \%: percent, 1.00: Reference group.

DOI: http://dx.doi.org/10.4314/ejhs.v28i6.3 


\section{DISCUSSION}

This study has assessed the prevalence and risk factors of CKD among diabetic adults at University of Gondar Hospital using an estimated glomerular filtration rate (eGFR) and urine albumin according to KDIGO guideline (1). The prevalence of CKD was $21.8 \%$ (95\% CI: $16 \%$ $27 \%)$. Of all our study participants, $9(3.9 \%)$ had renal impairment $\left(\right.$ eGFR $\left.<60 \mathrm{~mL} / \mathrm{min} / 1.73 \mathrm{~m}^{2}\right)$ and $46(20.1 \%)$ had albuminuria (Table 2). All of the participants who had renal impairment and of the with albminuria $(37 / 46,80 \%)$ were type 2 DM patients. Nine (3.9\%), 32(14.0\%), 8(3.5\%), and $1(0.4 \%)$ DM patients had an estimated GFR of $\geq 90 \mathrm{ml} / \mathrm{min} / 1.73 \mathrm{~m}^{2}$ (stage 1), $\quad 60-89.9$ $\mathrm{ml} / \mathrm{min} / 1.73 \mathrm{~m}^{2}$ (stage 2 ), $30-59.9 \mathrm{ml} / \mathrm{min} / 1.73 \mathrm{~m}^{2}$ (stage 3) and $<15 \mathrm{ml} / \mathrm{min} / 1.73 \mathrm{~m}^{2}$ (stage 5), respectively (Table 3 ).

Our estimate prevalence of CKD was lower than reports from Spain (27.9\%) (18), Netherlands (28\%) (19), UK (31\%) (20), Mediterranean area (34.1\%) (21), USA (39.6\%) (22) and Japan (42.3\%) (23). This difference in CKD prevalence might be because of the differences in case-mix (some of the studies included both type 1 and type 2 DM patients but others included only type 2 DM patients), creatinine and albumin assays, sample size and ethnic variations.

This study found a significant association between CKD and older age (AOR: 5.239, 95\% CI: 2.255-12.175). This result is consistent with other studies' outputs in various areas $(18,22,24-$ 26). As age increases, there is progressive loss of nephrons and decreased renal blood flow, which leads to CKD (27). It is reported that findings of renal insufficiency (eGFR $<60 \mathrm{~mL} / \mathrm{min} / 1.73 \mathrm{~m}^{2}$ ) and albuminuria become more prevalent in older age (28). Similarly, another study reported that individuals aged $\geq 65$ years had 101.5 and 2.5 times greater chance of developing renal insufficiency and proteinuria compared to their counterparts, respectively (29). Thus, screening of CKD in old age group is an important strategy to take an appropriate intervention.

CKD was independently associated with type 2 DM (AOR: 3.751, 95\% CI: 1.507-9.336) and longer duration of DM (AOR: 3.380, 95\% CI:
1.393-8.197) in our study subjects. This corresponds with the findings of several studies which reported that the likelihood of developing CKD was greater among patients with longer duration of diabetes $(24,30,31)$. CKD is estimated to affect $\sim 50 \%$ patients with type $2 \mathrm{DM}$. Improvement in cardiovascular survival in patient with type $2 \mathrm{DM}$ has contributed to patient surviving longer, allowing sufficient time to develop renal disease (32). However, CKD was not independently associated with type $2 \mathrm{DM}$ in Japanese study (23).

According to our study, elevated SBP (AOR: 3.633, 95\% CI: 1.597-8.265) was a risk factor for CKD. This was in agreement with other related studies, in which elevated SBP was independently associated with CKD $(18,33)$. The beneficial effects of controlling blood pressure (BP) and using antihypertensive agents for kidney function in diabetics has been described in current guidelines, which points out that control of BP reduce the rate of progression of renal disease in diabetes $(34,35)$.

Obesity was not independently associated with CKD in our study. However, it was associated by bivariate analysis (COR: 3.145, 95\% CI: 1.201-8.238). In addition, increased WC (AOR: $3.430, \quad 95 \%$ CI: 1.212-9.704) was independently associated with CKD in this study. Other similar studies reported as obesity was independent risk factor of $\operatorname{CKD}(36,37)$. This variation might be due to differences in lifestyles such as dietary habit, sedentary way of life and physical activities. In addition, our few sample size may affect the statistical tool to show the association between obesity and CKD. Obesity is associated with renal damage leading to albuminuria and poor outcomes of chronic kidney disease, pointing to the need for prevention $(38,39)$.

Single evaluation of eGFR and urine albumin may inflate the prevalence of CKD because of acute kidney infection and creatinine variability. We used dipstick method to measure urine albumin, and we were unable to calculate urine albumin-to-creatinine ratio to determine albuminuria. In addition, our sample size was relatively small and associations between 
different severity levels of CKD with risk factors have not been confirmed. Despite these, the results of this study are important in raising awareness of the community regarding CKD among DM patients at the study setting.

In conclusion, the present study identified high prevalence of chronic kidney disease among diabetic adults. Older age, elevated systolic blood pressure, increased waist circumference, type 2 diabetes mellitus, and longer duration of diabetes were independently associated with chronic kidney disease. Estimated glomerular filtration rate and albuminuria should be determined for diabetes mellitus patients at a regular interval of time for earlier diagnosis of chronic kidney disease to take an appropriate intervention.

\section{ABBREVIATIONS}

BMI: Body Mass Index; BP: Blood Pressure; CKD: Chronic Kidney Disease; CVD: Cardiovascular Disease; DBP: Diastolic Blood Pressure; DM: Diabetes Mellitus; eGFR: estimated Glomerular Filtration Rate; ESRD: End-Stage Renal Disease; GFR: Glomerular Filtration Rate; KDIGO: Kidney Disease Improving Global Outcome; MDRD: Modification of Diet in Renal Disease; SBP: Systolic Blood Pressure.

\section{ACKNOWLEDGEMENTS}

We would like to thank study participants for their willingness to give necessary information as well as blood and urine samples for this study. Our appreciation also goes to the University of Gondar Hospital Chronic Illness follow-up Clinic nurses and laboratory staff for their assistance during data collection period.

\section{REFERENCES}

1. Eknoyan G, Lameire N, Eckardt K, Kasiske B, Wheeler D, Levin A, et al. KDIGO 2012 clinical practice guideline for the evaluation and management of chronic kidney disease. Kidney International Supplements. 2013;3(1):5-14.

2. Levin A, Rocco M. KDOQI clinical practice guidelines and clinical practice recommendations for diabetes and chronic kidney disease. American Journal of Kidney Diseases. 2007;49(2):S10S179.

3. Naghavi M, Wang H, Lozano R, Davis A, Liang $\mathrm{X}$, Zhou $\mathrm{M}$, et al. Global, regional, and national age-sex specific all-cause and cause-specific mortality for 240 causes of death, 1990-2013: a systematic analysis for the Global Burden of Disease Study 2013. Lancet. 2015;385(9963):11771.

4. Schieppati A, Remuzzi G. Chronic renal diseases as a public health problem: epidemiology, social, and economic implications. Kidney International. 2005;68:S7-S10.

5. Hajhosseiny R, Khavandi K, Goldsmith D. Cardiovascular disease in chronic kidney disease: untying the Gordian knot. International journal of clinical practice. 2013;67(1):14-31.

6. Wali RK. Aspirin and the prevention of cardiovascular disease in chronic kidney disease: time to move forward?. Journal of the American College of Cardiology. 2010;56(12):966-8.

7. Naicker S. End-stage renal disease in sub-Saharan Africa. Ethnicity \& disease. 2009;19(1):13.

8. Levey AS, Eckardt K-U, Tsukamoto Y, Levin A, Coresh J, Rossert J, et al. Definition and classification of chronic kidney disease: a position statement from Kidney Disease: Improving Global Outcomes (KDIGO). Kidney International. 2005;67(6):2089-100.

9. Go AS, Chertow GM, Fan D, McCulloch CE, Hsu C-y. Chronic kidney disease and the risks of death, cardiovascular events, and hospitalization. New England Journal of Medicine. 2004;351(13):1296-305.

10.Jha V, Garcia-Garcia G, Iseki K, Li Z, Naicker S, Plattner B, et al. Chronic kidney disease: global

DOI: http://dx.doi.org/10.4314/ejhs.v28i6.3 
dimension and perspectives. The Lancet. 2013;382(9888):260-72.

11. National Kidney Foundation. K/DOQI Clinical Practice Guidelines for Chronic Kidney Disease: Evaluation, Classification and Stratification. American journal of kidney disease. 2002;39(suppl 1):S1-S266.

12. Couser WG, Remuzzi G, Mendis S, Tonelli M. The contribution of chronic kidney disease to the global burden of major noncommunicable diseases. Kidney International. 2011;80(12):1258.

13. Barsoum RS. Chronic kidney disease in the developing world. The New England journal of medicine. 2006;354(10):997-9.

14. Guariguata L, Whiting DR, Hambleton I, Beagley J, Linnenkamp U, Shaw JE. Global estimates of diabetes prevalence for 2013 and projections for 2035. Diabetes Research and Clinical Practice.103(2):137-49.

15. Fiseha T, Kassim M, Yemane T. Prevalence of chronic kidney disease and associated risk factors among diabetic patients in southern Ethiopia. American Journal of Health Research. 2014;2(4):216-21.

16. National Cholesterol Education Program. Expert Panel on Detection, Evaluation, and Treatment of High Blood Cholesterol in Adults (Adult Treatment Panel III): Third Report of the National Cholesterol Education Program (NCEP) Expert Panel on Detection, Evaluation, and Treatment of High Blood Cholesterol in Adults (Adult Treatment Panel III) final report. Circulation. 2002;106(25).

17.Levey AS, Greene T, Kusek JW, Beck GJ. A simplified equation to predict glomerular filtration rate from serum creatinine. Journal of the American Society of Nephrology. 2000;11:155A.

18. Rodriguez-Poncelas A, Garre-Olmo J, FranchNadal J, Diez-Espino J, Mundet-Tuduri X, BarrotDe la Puente J, et al. Prevalence of chronic kidney disease in patients with type 2 diabetes in Spain: PERCEDIME2 study. BMC nephrology. 2013;14:46.

19. Victor van der Meer, H Petra M Wielders, Diana C Grootendorst, Joost S de Kanter, Yvo WJ Sijpkens, Willem JJ Assendelft, et al. Chronic kidney disease in patients with diabetes mellitus type 2 or hypertension in general practice. British Journal of General Practice. 2010;60:884-90.

20. New J, Middleton R, Klebe B, Farmer C, De Lusignan S, Stevens $\mathrm{P}$, et al. Assessing the prevalence, monitoring and management of chronic kidney disease in patients with diabetes compared with those without diabetes in general practice. Diabetic medicine. 2007;24(4):364-9.

21.Coll-de-Tuero G, Mata-Cases M, RodriguezPoncelas A, Pepió JM, Roura P, Benito B, et al. Chronic kidney disease in the type 2 diabetic patients: prevalence and associated variables in a random sample of 2642 patients of a Mediterranean area. BMC nephrology. 2012;13:87.

22.Plantinga LC, Crews DC, Coresh J, Miller ER, Saran R, Yee J, et al. Prevalence of chronic kidney disease in US adults with undiagnosed diabetes or prediabetes. Clinical Journal of the American Society of Nephrology. 2010;5:673-82.

23. Ohta M, Babazono T, Uchigata Y, Iwamoto Y. Comparison of the prevalence of chronic kidney disease in Japanese patients with Type 1 and Type 2 diabetes. Diabetic medicine. 2010;27(9):1017.

24. Middleton RJ, Foley RN, Hegarty J, Cheung CM, McElduff P, Gibson JM, et al. The unrecognized prevalence of chronic kidney disease in diabetes. Nephrology Dialysis Transplantation. 2006;21:88-92.

25.De Boer IH, Rue TC, Hall YN, Heagerty PJ, Weiss NS, Himmelfarb J. Temporal trends in the prevalence of diabetic kidney disease in the United States. Journal of the American Medical Association. 2011;305(24):2532-9.

26. Bailey RA, Wang Y, Zhu V, Rupnow MF. Chronic kidney disease in US adults with type 2 diabetes: an updated national estimate of prevalence based on Kidney Disease: Improving Global Outcomes (KDIGO) staging. $B M C$ Research Notes. 2014;7:415.

27. WINEARLS DO. Ageing and the glomerular filtration rate: truths and consequences. Transactions of the American Clinical and Climatological Association. 2009;120:419-28.

28. Garg AX, Kiberd BA, Clark WF, Haynes RB, Clase CM. Albuminuria and renal insufficiency prevalence guides population screening: results 
from the NHANES III. Kidney International. 2002;61(6):2165-75.

29. Chadban SJ, Briganti EM, Kerr PG, Dunstan DW, Welborn TA, Zimmet PZ, et al. Prevalence of kidney damage in Australian adults: The AusDiab kidney study. Journal of the American Society of Nephrology. 2003;14(suppl 2):S131-S8.

30. Low S, Sum CF, Yeoh LY, Tavintharan S, Ng $\mathrm{XW}$, Lee S, et al. Prevalence of chronic kidney disease in adults with type 2 diabetes mellitus. Annals of the Academy of Medicine, Singapore. 2015;45(5):164-71.

31. Narenpitak S, Narenpitak A. Prevalence of chronic kidney disease in type 2 diabetes in primary health care unit of Udon Thani province, Thailand. Medical journal of the Medical Association of Thailand. 2008;91(10):1505-13.

32. Thomas MC, Cooper ME, Zimmet P. Changing epidemiology of type 2 diabetes mellitus and associated chronic kidney disease. Nature Reviews Nephrology. 2016;12(2):73-81.

33. Afolabi MO, Abioye-Kuteyi EA, Arogundade FA, Bello IS. Prevalence of chronic kidney disease in a Nigerian family practice population. South African Family Practice. 2009;51(2):132-7.

34. Crowe E, Halpin D, Stevens P. Guidelines: early identification and management of chronic kidney disease: summary of NICE guidance. British Medical Journal. 2008;337(7673):812-5.

35.Levin A, Hemmelgarn B, Culleton B, Tobe S, McFarlane P, Ruzicka M, et al. Guidelines for the management of chronic kidney disease. Canadian Medical Association Journal. 2008;179(11):1154.

36. Stengel B, Tarver-Carr ME, Powe NR, Eberhardt MS, Brancati FL. Lifestyle factors, obesity and the risk of chronic kidney disease. Epidemiology. 2003;14(4):479-87.

37.Wang Y, Chen X, Song Y, Caballero B, Cheskin L. Association between obesity and kidney disease: a systematic review and meta-analysis. Kidney International. 2008;73:19-33.

38. Wahba IM, Mak RH. Obesity and obesityinitiated metabolic syndrome: mechanistic links to chronic kidney disease. Clinical Journal of the American Society of Nephrology. 2007;2(3):550.

39. Eknoyan G. Obesity and chronic kidney disease. Nefrologia. 2011;31(4):397-403. 